\section{Laboratory animals unprotected}

Tokyo

Debate over the welfare of laboratory animals in Japan has been sparked by reports from a French scientist that monkeys at Kyoto University's Inuyama Primate Research Institute have been shamefully maltreated. Bernadette Brésard, who carried out research at the institute last year, has revealed to French magazines that monkeys were routinely restrained in "monkey chairs" for months on end. Behind this one incident lies a much deeper problem: the lack of clear, enforceable regulations on the treatment of laboratory animals in Japan.

Brésard came to Japan last year with an

\section{Eiffel in orbit}

French engineers, clearly inspired by the recent refurbishment and laser-lighting of the French-built Statue of Liberty in New York, are now planning to put an Eiffel Tower in space.

The object of a competition, announced last month by the Eiffel Tower Company (Société Nouvelle d'Exploitation de la Tour Eiffel), is to design a structure for the space age "as audacious and imaginative as that of Gustave Eiffel for the age of steam". Designs must be for a durable structure visible to the naked eye and symbolizing

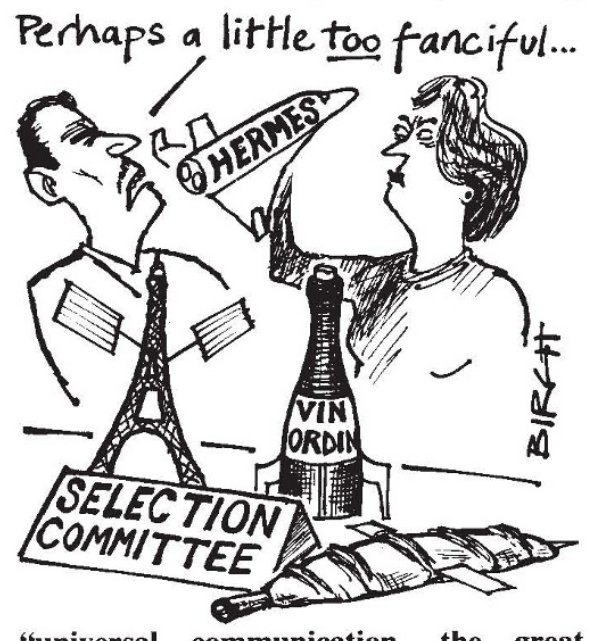

"universal communication, the great dream of our times". Otherwise, the structure is to be useless: it must have "no commercial or military function", but "peaceful" and "scientific" uses can be considered. The three best projects will be selected by a jury of scientist, space engineers and artists this October, for prizes of up to $\$ 20,000$. There will also be a junior category for under-15s. Actual construction of the winners' projects, however, is not guaranteed.... Further information may be obtained from: La Tour Eiffel de l'Espace, Champ de Mars, 75007 Paris, France.

Robert Walgate orang utan, Dou-dou, and a chimpanzee, Chloé, which were exchanged for Japanese macaques from Inuyama. The Inuyama centre, funded by the Ministry of Education, Science and Culture (MESC), was set up as the nations's key primate research centre. But after being recruited by MESC to continue her research on cognitive ethology Brésard soon found herself embroiled in an arguement.

The monkeys were confined day and night for several months in makeshift chairs with a stock-like clamper device around their necks so that electrical recordings could easily be taken from their brains. The monkeys' necks became ulcerated and their testicles degenerated because of the prolonged immobilization.

Horrified by the monkeys' condition, Brésard requested their immediate release, but she was told by members of the psychology department to which she belonged that they had "no right to ask the researchers to release their monkeys as long as they considered it essential for their experiments". Instead, Brésard was nominated to join an informal working group on animal welfare set up by associate professor Toshio Asano of the psychology department who also chaired the institute's ad hoc animal welfare committee. But, frustrated by the working group's prolonged deliberations, Brésard turned to the French magazines, Geo and La vie des bêtes.

No sooner did the articles appear than the Japanese embassies in France and Switzerland were inundated with complaints and the Foreign Ministry asked MESC to investigate. But the Inuyama researchers pointed out that they had been acting within Japanese law and government guidelines.

Whereas Western nations have been tightening up guidelines and introducing new laws, Japan still has regulations that are full of loopholes and leave interpretation largely to the "common sense" of the researcher. For example, in Article 5 of the guidelines issued by the Prime Minister's office in 1980, researchers are told to "minimize the pain and suffering of laboratory animals by, for example, giving anesthetics", "provided this does not interfere with the purpose of the experiment".

The regulations have no teeth. There is no system of licensing or government inspection to check that researchers follow the guidelines, no process of review of research proposals, and no requirement to report the number or type of animals used or the experiments carried out. Hence the fine of up to 30,000 yen $(£ 120)$ for cruel treatment has little chance of being levied.

There are no vociferous anti-vivisectionist groups in Japan campaigning for animal rights, as there are in the West. The Japan Animal Welfare Society is a moderate group that seeks to reduce experimentation on animals and to alleviate their suffering.

Recognizing that Japan lags behind in animal welfare, the Inuyama ad hoc committee headed by Asano drew up guidelines for the care and use of laboratory primates based on the US National Institutes of Health 1985 guide. Published in April shortly after Brésard left, the Inuyama guide is backed up by an institutional monitoring committee composed of faculty members, including at least one

\section{IMAGE UNAVAILABLE FOR COPYRIGHT REASONS}

who is involved in animal experiments; one who is not; and a veterinarian.

With implementation of the guide, conditions for the restrained monkeys have been considerably improved at Inuyama, says Asano. Chairing beyond 24 hours is no longer permitted without consent from the monkey committee, and no requests for chairing beyond 24 hours have so far been made. When the monkeys are not being used for experiments, attempts are made to bring them together in social groups. Minimum cage sizes are defined and, although cages at Inuyama do not all come up to standard, Asano says they will soon get the 300 cages they require, despite a price of about 150,000 yen (£600) per cage.

The Inuyama guide is now attracting attention. At the annual convention of the Primate Society of Japan in Nagoya in mid-June, members were urged to draw up their own guidelines following that of Inuyama. But the Inuyama guide avoids discussion of an issue that has dominated debate in the West; pain in laboratory animals.

A symposium on this topic was held in Tokyo at the end of May by the Laboratory Animal Society of Japan, but the participants tied themselves up in semantic knots and no significant progress was made.

Although changes have now been made at Inuyama, other institutes are under no obligation to adopt new guidelines. Nor is there any way of checking up what conditions are like in private industry, where there is no requirement to report experiments. Changes in legislation are not at present being considered by the government, but there may be changes in attitude if concerned groups continue to grow in strength.
David Swinbanks 